\title{
HOW DO SEDIMENTATION EVENTS TRIGGER GEOCHEMICAL PROCESSES?
}

LUCIE PASTOR ${ }^{1}$, MARK ZINDORF ${ }^{1}$, JURJEN ROOZE ${ }^{2}$, CHRISTOF MEILE ${ }^{2}$, CHRISTOPHE BRANDILY ${ }^{1}$, SABINE SCHMIDT $^{3}$, GWENAEL JOUET $^{4}$

${ }^{1}$ Ifremer, centre de Brest, REM/EEP/LEP

${ }^{2}$ Department of Marine Sciences, University of Georgia

${ }^{3}$ UMR CNRS 5805 EPOC - OASU, Université de Bordeaux

${ }^{4}$ Ifremer, centre de Brest, REM/GM/LGS

Transfer of sediment from rivers to the continental margin can trigger a wide range of biogeochemical processes. By looking at sediment units deposited during short time events like river floods and resuspension episodes, or at a sediment column retracing changes in the sedimentation accumulation rate over geological times, we can identify and quantify the impact of such events on specific geochemical processes.

In this study, we give an overview of several locations where the sediment deposition patterns led to drastic changes in geochemical profiles. We will travel from the Rhône River prodelta area to the Mozambique Channel. The Rhône prodelta undergoes highly variable deposition phases with sediment originating from several catchments, affecting the manganese cycle. On the continental slope of NW Madagascar, the Mahavavy delta progradation associated with extreme climatic events led to episodic reconnection between the river and the canyon and to subsequent episodic sedimentation events. These inputs, rich in iron oxides, impact the $\mathrm{Fe}$ and $\mathrm{S}$ cycles. Finally, in the deposition center off the Zambezi River, past changes in sediment accumulation rates and organic matter deposition provoked a vertical shift of the sulfate-methane-transition zone around 14 ka BP, leading to several peaks of pyrite in the sedimentary column.

This research was co-funded by TOTAL and IFREMER as part of the PAMELA scientific project, by the French national ANR program CHACCRA (contract number ANR-VULN06-001-01) and the French INSU-EC2CO program RiOMar.fr. 